\title{
ADORNANDO EL CUERPO FEMENINO: OBJETOS DE MODA Y GÉNERO EN LA DE BRINGAS (1884) DE BENITO PÉREZ GALDÓS
}

\author{
INÉS CORUJO MARTÍN \\ New York City College of Technology (CUNY)
}

\begin{abstract}
El presente artículo explora la relevancia sociocultural que adquieren los objetos de vestir femeninos en La de Bringas (1884) de Benito Pérez Galdós. Las prendas en la novela conforman un espacio discursivo a partir del cual es posible aproximarse desde una lente crítica a la compleja relación que la mujer estableció con el proyecto decimonónico de la modernidad. A través de su interacción con artículos de moda, la protagonista Rosalía de Bringas forja una identidad moderna, evadiéndose de los límites domésticos marcados por la estructura patriarcal y rebasando el arraigado modelo de "ángel del hogar". Asimismo, este artículo analiza la emergencia de espacios urbanos que, como el comercio Sobrino Hermanos retratado en La de Bringas, favorecieron el ingreso de la mujer en la esfera pública de la segunda mitad del XIX.
\end{abstract}

PALABRAS CLAVE: objetos, moda, modernidad, género, Pérez Galdós, literatura española decimonónica.

Decorating the Female Body: Fashion Objects and Gender in La de Bringas (1884) by Benito Pérez Galdós

This essay explores the sociocultural relevance acquired by women's clothing objects in Benito Pérez Galdós's La de Bringas (1884). The garments depicted in the novel constitute a discursive space to critically approach the complex relationship women established with modernity. Through her interaction with fashion objects, protagonist Rosalía de Bringas forges a modern identity, transcending domestic boundaries marked by the patriarchal structure, beyond the conventional image of the "angel of the home". Likewise, this article addresses the importance of urban spaces that, like the Sobrino Hermanos store depicted in La de Bringas, favored women's entry into the public sphere in the second half of the nineteenth century.

KEY WORDS: objects, fashion, modernity, gender, Pérez Galdós, nineteenth-century Spanish literature.

Inserta dentro del ciclo de novelas contemporáneas de Benito Pérez Galdós, La de Bringas (1884) relata las aspiraciones sociales de la burguesa Rosalía Pipaón en el bullente Madrid comercial anterior al derrocamiento de la monarca

Corujo Martín, Inés (2020), "Adornando el cuerpo femenino: objetos de moda y género en La de Bringas (1884) de Benito Pérez Galdós", Lectora, 26: 67-81. ISSN: 1136-5781 D.O.I.: 10.1344/Lectora2020.26.5, icorujom@gmail.com

Recepció: 15 de desembre de 2019 - Acceptació: 15 d'abril de 2020 
Isabel II. ${ }^{1}$ La desmedida afición por la indumentaria que se apodera de la protagonista ocupa un lugar central en la trama, influyendo de forma directa en el desenvolvimiento narrativo. Las detalladas referencias al atuendo femenino no han pasado desapercibidas a la crítica, como avalan diversas investigaciones dedicadas al tema. Así, mientras Dorota Heneghan (2015) vincula el papel de la moda a la problemática construcción del género en las últimas décadas del XIX, la tesis doctoral inédita de Marta Blanco Carpintero (2010) desentraña las múltiples significaciones que presenta la indumentaria en la producción literaria galdosiana. ${ }^{2}$

Enlazando con los estudios emprendidos hasta la fecha, en este artículo propongo un análisis de la novela enfocado en la relevancia sociocultural que adquieren los objetos de vestir femeninos. La proliferación de prendas y accesorios en el texto, rebasando una mera funcionalidad decorativa y anecdótica, conforma un espacio discursivo idóneo para aproximarse desde una lente crítica a la compleja relación que la mujer estableció con el proyecto de la modernidad decimonónica. A través de sus compras e interacción con artículos de moda, Rosalía de Bringas participa del espíritu de la modernidad en boga, delineando una incipiente identidad moderna. Por otro lado, con la penetración de la modernización en la cultura occidental, emergen los grandes comercios y almacenes que, destinados al consumo femenino, se caracterizan por el exceso y acumulación de objetos materiales. Ingresando en espacios urbanos como la madrileña tienda Sobrino Hermanos, donde las divisiones sociales se difuminan y la mujer llega a alcanzar cierta autonomía monetaria, Rosalía logra evadirse de su reglamentada realidad doméstica y social. En mi análisis, la evasión de la protagonista se produce por medio de artefactos materiales que permiten, si bien sea de manera alegórica y efímera, reimaginar su sentido del yo y resignificarse socialmente.

\footnotetext{
${ }^{1}$ Pérez Galdós ambienta el ciclo de sus novelas contemporáneas, publicadas entre 1881 y 1889, en los años anteriores a la Restauración (desde 1868 hasta el retorno borbónico en 1874 con Alfonso XII). Se trata de un periodo convulso de cambios políticos, golpes de Estado, guerras carlistas y transformaciones sociales que el autor canario ficcionaliza fijándose en la mesocracia madrileña.

${ }^{2}$ Otros estudios pertinentes para este análisis se deben a Luis Fernández Cifuentes y Roxana Pagés Rangel (2005); Ana María Díaz Marcos (2006); Noël Valis (2003); Akiko Tsuchiya (1993); y Silvia Tubert (1997). Los autores citados hacen referencia, de manera explícita o tangencial, a la vestimenta y cultura material en La de Bringas. Por ejemplo, Tsuchiya interpreta el aspecto sartorial bajo el prisma de una sexualidad reprimida, mientras que Valis identifica la debilidad de Rosalía por la ropa como un tipo de cursilería. Por su parte, Tubert elabora una lectura psicoanalítica basada en el erotismo que desprenden telas y adornos.
}

68

Lectora, 26 (2020): 67-81. ISSN: 1136-5781 D.O.I.: 10.1344/Lectora2020.26.5 


\section{El género de la modernidad}

La "modernidad" constituye uno de los términos que mayor interés ha acaparado en los estudios culturales contemporáneos y que, significativamente, menos consenso académico ha recibido. En líneas generales, este fenómeno se entiende como la respuesta estético-cultural a una nueva forma de captar la organización del mundo afectada por los efectos socioeconómicos de la modernización, tales como el desarrollo industrial, la proliferación del periodismo, revolución en los patrones del consumo, urbanización y explosión de la clase media. En esta línea, Rita Felski explica que "modernidad" se aplica tanto al proceso de industrialización y urbanización que caracteriza la modernización como "the more general experience of aestheticization of everyday life, as exemplified in the ephemeral and transitory qualities of an urban culture shaped by the imperatives of fashion, consumerism, and constant innovation" (1995: 13).

Es preciso anotar que los teorizadores pioneros de la modernidad asocian este fenómeno con lo femenino y le atribuyen un marcado rasgo de género. Así, Charles Baudelaire, en su ensayo seminal The Painter of Modern Life (1863), conceptualiza la modernidad empleando imágenes de mujeres: la prostituta, la mujer estéril, la lesbiana o el andrógino, además de dedicar prolijas descripciones a la indumentaria femenina. De acuerdo con su argumentación, la moda encarna "lo efímero, lo fugitivo y lo contingente" (1964: 13), tres rasgos que capturan a la perfección la naturaleza volátil de los tiempos modernos. Por su parte, Walter Benjamin integra lo femenino en su singular creación de la fantasmagoría y el autómata en su inconclusa The Arcades Project (1982). ${ }^{3}$ En palabras de Benjamin, "The woman is the object in the modern streets" (1999: 343, 617) y lo femenino es esencial para la construcción simbólica del orden moderno. El pensador alemán expresa que la modernidad se materializa en artefactos culturales y en espacios en los cuales priman lo femenino y lo material: muñecas-maniquí, grandes almacenes y las exhibiciones parisinas de Granville. Benjamin otorgan ostensible importancia a los objetos de moda, ya que actúan como repositorios de emociones y memoria cultural, condensando en su materialidad el espíritu de la modernidad (1999: 354).

Si bien diversas investigaciones en las últimas décadas han afianzado la íntima conexión entre género y modernidad en el XIX, en el campo de los estudios ibéricos, destaca la ausencia de trabajos que aborden dicha relación en base a objetos, artefactos y significantes materiales. ${ }^{4}$ La imbricación entre modernidad y género puede

\footnotetext{
${ }^{3}$ The Arcades Project fue publicado póstumamente en 1982, mas escrito por Benjamin entre 1827 y 1940.

${ }^{4}$ Libros de publicación reciente enfocados en objetos de vestir se deben a Susan Hiner (2010) y Ariel Beaujout (2011), incluidos en la sección bibliográfica. Si bien artículos como el de Jo Labanyi "Doing Things: Emotion, Affect, and Materiality” (2010) y la introducción de Pura Fernández, Luisa Elena
} 
constatarse no solo en la cultura escrita y visual del momento, sino además en determinados objetos de uso cotidiano que obtuvieron un determinante papel a la hora de introducir a la mujer en los espacios simbólicos de la modernidad, colaborando en la configuración de una experiencia urbana femenina. A este respecto, mi estudio conecta con la corriente teórica de los "nuevos materialismos" que analiza de qué manera objetos, cosas y artefactos se inscriben en la historia cultural y operan como agentes productivos que intervienen en el mundo social (Tilley, 2006: 10). En líneas generales, los nuevos materialismos, surgidos en los años 1980 y 1990 con el fundacional ensayo de Arjun Appadurai The Social Life of Things (1988), buscan revalorizar la importancia del plano material en la cultura y vida diaria. Para el antropólogo, los objetos materiales, lejos de constituir una categoría inerte, inmóvil y pasiva, se hallan revestidos de vida social (1988: 4). Como argumenta, las relaciones sociales humanas son mediadas a través de objetos y los sistemas sociales se vuelven significativos (o no) en base a ellos. Las identidades a su vez se forjan con relación a la cultura material, siendo resultado de la negociación de significados entre el plano de lo material y lo simbólico (1988: 5-7).

Por otra parte, en este artículo reconozco la influencia de dos publicaciones recientes en los estudios de género: Material Women, 1750-1950 (Goggin y Tobin, 2009) y Materializing Gender in Eighteenth Century Europe (Germann y Strobel, 2006). Dichos volúmenes demuestran de qué forma la representación visual y textual de bienes materiales femeninos no solo refleja, sino que colabora en la producción de categorías identitarias de género, raza, clase social y nación. Como se lee en la introducción de Jennifer Germann y Heidi Strobel: "Women in the process of making and manipulating things were not only engaged in self-definition and identity performance, but they were actively engaged in meaning-making practices that involved the construction, circulation and maintenance of knowledge" (2016: 4). De manera similar, la interrelación que se desarrolla entre Rosalía y sus objetos en La de Bringas contribuye a redefinir la noción decimonónica de la feminidad y la posición social de la mujer dentro de la sociedad española moderna.

\section{Los objetos de vestir como fuente de creatividad estética para la mujer}

Como apunta el historiador de la moda James Laver, la proliferación y globalización de la indumentaria femenina irrumpen en la cultura occidental decimonónica de

Delgado y Jo Labanyi al volumen colectivo Engaging the Emotions in Spanish Culture and History (2015), abordan los nuevos materialismos en los estudios literarios y culturales hispánicos, haciendo hincapié en las emociones como una categoría de análisis histórico, no profundizan en cómo objetos y artefactos materiales colaboran en la construcción de categorías identitarias, objetivo de este artículo.

70

Lectora, 26 (2020): 67-81. ISSN: 1136-5781 D.O.I.: 10.1344/Lectora2020.26.5 
manera casi revolucionaria (1945: 70). Si, como expresa Elizabeth Wilson, "fashion is obsessed with gender, defines and redefines the gender boundary", en la segunda mitad de la centuria, la vestimenta se convierte en un poderoso identificador de género y clase social (1987: 117). Nunca en toda la historia del traje ha sido tan marcada la diferencia entre el vestido masculino y femenino, ni tan escindidas las siluetas del hombre y la mujer (Entwistle, 2000: 156). La moda aparece así estrechamente ligada a lo femenino, mientras que la modernidad halla en la moda su más acabada expresión y materialización estética. ${ }^{5}$

En La de Bringas, los trajes y accesorios de la burguesa Rosalía Pipaón, caracterizados por variadas combinaciones de tejidos y colores, se trasladan al primer término narrativo. Ante la severa advertencia de su esposo, el funcionario real don Francisco Bringas, que insta a su esposa a atenerse a la sobria economía del hogar - "te arreglarás con los vestidos que tienes. Los mudas, los cambias, le quitas a uno una cosa para ponérsela a otro [...] y como nuevo" (178)—, Rosalía introduce pequeños cambios interminables a sus prendas. De este modo, "A cencerros tapados Rosalía estaba siempre haciendo reformas, combinando trapos e interpretando más o menos libremente lo que traían los figurines" (93). Más adelante se nos dice que "[Rosalía disponía] varios arreglos, alargando unas cosas, reformando completamente otras" (164). Tras procurarse telas y materiales en diversos comercios, pasa el tiempo de espaldas a don Francisco, empalmando pedazos de tela y disimulando remiendos recluida en su espacio doméstico a medio camino entre guardarropa y alcoba, el Camón. Sus compras "eran retales, pedacitos o alguna tela anticuada, para hacer combinaciones en casa y refundir lo viejo dándole viso y representación de novedad" (97). En el Camón, los cajones de la cómoda están atestados de pedazos de tela, algunos cortados, otros por cortar y, en un enorme baúl, Rosalía guarda mil especies de arreos diversos. El Camón se trata de un lugar determinado por lo material, por la circulación y movimiento de objetos de moda, lo que establece paralelismo con la algarabía de trapos en el comercio Sobrino Hermanos (119). La superabundancia y saturación de objetos se desarrolla en esta pieza recóndita y cerrada a la que solo tienen acceso las mujeres. Una alcoba doméstica y feminizada donde la visibilidad y el ocultamiento, el placer y el desasosiego,

\footnotetext{
${ }^{5}$ En The Psychology of Clothes (1930), John Carl Flügel se refiere a este hecho como "La Gran Renuncia Masculina", que explica la mayor sobriedad de la indumentaria masculina frente a los excesos y recargamientos de la femenina. No obstante, las ideas de Flügel han sido revisadas en recientes publicaciones. The Hidden Consumer: Masculinities, Fashion and City Life, 1860-1914 de Cris-topher Breward (1999) y la tesis doctoral inédita de Abigail Joseph, Queer Things. Victorian Objects and the Fashioning of Homosexuality (2012), demuestran que el hombre burgués participó activamente en la moda decimonónica, como demuestran las figuras del dandi y el flanêur.
} 
manifiestan la compleja dialéctica que se desarrolla entre el objeto y el cuerpo femenino.

La vestimenta de la heroína galdosiana, influenciada por el estilo parisino en boga del Segundo Imperio francés, se basa en el montaje errático de telas y en la múltiple variedad de colores y estilos. A este respecto, Carlos Soldevila explica que los trajes de mujer en la segunda mitad del siglo se caracterizaban por la combinación cromática y el abigarramiento textil (1950: 44-45). El atuendo de Rosalía articula un fluido mosaico en constante proceso de metamorfosis que proyecta una multiplicidad de perspectivas. El caos de cintas, plumas, encajes y otros adornos nunca conforma un equipo unificado, sino que se dispersa en múltiples imágenes fragmentarias en proceso de construcción, lo que transmite el carácter dinámico de la modernidad. Si Benjamin define la metrópoli como una entidad en expansión marcada por la discontinuidad, la dislocación y la fragmentación, sin percepción definitiva de la totalidad, la indumentaria de Rosalía conforma un híbrido ensamblaje de mezclas inesperadas e indescifrables, incapaces de ser reducidas a una interpretación unidimensional y unívoca (Gilloch, 1988: 182).

Gracias a los ferrocarriles y a las nuevas políticas de arancel de aduanas de libre comercio en España, crece la popularidad y venta de novedades extranjeras, en especial francesas (Rodríguez, 1985: 166). A lo largo de la novela son frecuentes las referencias a la moda de París, la capital de la modernidad por excelencia que dicta las últimas tendencias sartoriales. Como señala la historiadora de la moda Valerie Steele, durante el XIX París se hace con la hegemonía de la alta costura, erigiéndose como el núcleo de la moda (1988: 80). La rica variedad de telas y objetos franceses que circulan en La de Bringas indica su rápida producción y fácil disponibilidad en los comercios de la burguesía madrileña. A través de la expansión de artículos provenientes de París, el texto capta la ilusión de progreso y la naturaleza dinámica de la modernidad que se experimentaban en el Madrid del momento.

La moda constituye una importante fuente de creatividad estética que alienta la imaginación material de Rosalía. Varias escenas en la novela describen su aderezo frente a la luna del espejo del Camón recomponiendo su atuendo. Como se lee, "[Rosalía] sacaba faldas, cuerpos pendientes de reforma, pedazos de tela cortada o por cortar, tiras de terciopelo y seda; y poniéndolo todo sobre un sofá, sobre sillas, baúles o en el suelo si era necesario, empezaba un febril consejo sobre lo que debía hacer para lograr el efecto mejor y más llamativo" (94). En otra ocasión, la de Bringas concibe unos faldones con "gros glasé, color cenizas de rosa [...] glasé verde naciente y tres o cuatro botones verdes", sin imitar los figurines franceses de las revistas y haciendo uso exclusivo de su propia inventiva (93). Rosalía se infiltra en la esfera urbana y en la emergente sociedad capitalista desplegando una constante actividad consumista. De acuerdo con Don Slater, el consumo femenino en el XIX constituye un vehículo para la autonomía, subjetividad, privacidad y libertad de la mujer (1997: 31). Al hilo de

72 Lectora, 26 (2020): 67-81. ISSN: 1136-5781 D.O.I.: 10.1344/Lectora2020.26.5 
esto, la indumentaria de la protagonista no detenta una presencia silenciosa ni secundaria en la novela, sino que contribuye a transmitir sus fantasías y anhelos frustrados; simboliza su intento por salirse de los límites domésticos marcados y reinventar su identidad, escapando de una cotidianidad opresiva. El consumo y adquisición de objetos, de esta forma, favorecen que la mujer reconstruya su sentido del yo a través de lo material.

A este hecho contribuye la fundación de los grandes almacenes, espacios urbanos destinados al consumo, preferentemente femenino, construidos a imitación de los primeros fundados en París. ${ }^{6}$ Casa Sobrino Hermanos en La de Bringas, ubicada en el centro madrileño, encarna la meca de la modernidad en el panorama comercial de 1868. En este tipo de locales, mujeres de la clase media como Rosalía ejercen cierta capacidad de acción monetaria y se introducen en la red comercial, rompiendo con el constreñido espacio doméstico. Michael B. Miller describe los grandes almacenes como un quimérico país de colores, sensaciones y sueños con rebajas, pago a crédito, vendedores galantes y entrada libre para mujeres de todas las clases sociales, donde también era posible examinar los productos expuestos sin obligación de comprarlos (1981: 169). Rosalía descubre en Sobrino Hermanos un lugar idóneo para dar rienda suelta a su ingenio sartorial en oposición al austero control económico ejercido por don Francisco.

Los grandes almacenes, en comparación con las pequeñas tiendas o ultramarinos, incorporan un signo de modernidad en las relaciones sociales. Ofrecen un lugar social más neutro, de lujo democratizado, donde se desdibujan las rígidas divisiones jerárquicas que antaño habían señalado quién podía comprar en las tiendas (Lancaster, 1995: 31). Los grandes almacenes seducen a todos los niveles socioeconómicos y otorgan a las clases medias la ilusión de pertenecer a un estrato social elevado. Como documenta el historiador Philippe Perrot, la moda es un fenómeno decimonónico que florece como consecuencia de la transformación del sistema de estratificación social impuesto por la modernidad occidental; el triunfo financiero de la burguesía europea generalizó el acceso a la moda, anteriormente un lujo monopolizado por la aristocracia (1994: 7). La novela galdosiana plasma dicha realidad socioeconómica a partir del incesante consumo que tiene lugar en Casa Sobrino Hermanos, un espacio convertido en motor de las modernas relaciones sociales. Rosalía de Bringas, nacida en el seno de una rancia familia de burócratas, accede mediante sus visitas a Casa Sobrino Hermanos al mundo aristocrático, compitiendo en galas y elegancia con damas de la más alta alcurnia. Por medio de

\footnotetext{
${ }^{6}$ El primer centro comercial documentado en Madrid fue el Madrid-París en la Gran Vía, edificado en 1923, mientras que en Barcelona fue El Siglo en 1878. En este punto, es vital hacer referencia a la novela de Émile Zola El paraíso de las damas (1883), cuya acción se desenvuelve por entero en los grandes almacenes parisinos Bon Marché.
} 
objetos, participa en el espectáculo social de la moda, sintiéndose parte de una clase social privilegiada que no le pertenece por nacimiento.

Como Rosalía aprende pronto, las relaciones con miembros de la aristocracia imponen deberes ineludibles, entre los que la vestimenta cumple una función crucial. El vestido y el adorno son una inversión económica que aseguran el acceso a un estrato social alto dentro de una sociedad subyugada por el poder de las apariencias. Gracias a su esmerado atuendo, Rosalía tiene la oportunidad de entablar relación con damas nobles como Milagros, la marquesa de Tellería, una aristócrata "con refinado gusto en artes de vestimenta" y "exquisito gusto en materia de trapos y modas" (91). La marquesa, a causa de su virtuoso dominio sartorial, se convierte en el modelo de elegancia para Rosalía y ejerce sobre ella más influjo que su propio esposo (92). Así, la moda suscita un aparente sentido de movilidad social, reflejando el giro en la estratificación jerárquica que estaba teniendo lugar en la sociedad española.

En Sobrino Hermanos, Rosalía admira absorta el contenido de las cajas blancas "donde se archivan los sueños de las damas" (98). El acto de recibir prendas nuevas alivia sus sufrimientos personales y favorece la formación de una identidad alternativa, más allá de su papel de esposa, madre y "ángel del hogar". El entorno persuasivo de los establecimientos comerciales son el único lugar donde cobran vida sus genuinas emociones y disfruta de cierto grado de libertad. El tiempo que dedica para salir de compras con su amiga la marquesa Milagros por la ciudad, moviéndose de tienda en tienda, es el que reconoce como más dichoso: "Ratos felices eran para Rosalía estos que pasaba con la marquesa discutiendo la forma y manera de arreglar sus vestidos. Pero el gozo mayor de ella era acompañar a su amiga a las tiendas, aunque pasaba desconsuelos por no poder comprar las muchísimas cosas buenas que veía. El tiempo se les iba sin sentirlo" (97).

Rosalía pronto descubre que Sobrino Hermanos ofrece pago a crédito, el incentivo más fuerte que le anima a hacerse con un amplio surtido de prendas y accesorios. Este tipo de transacción a largo plazo propicia que no medite en las compras ni regatee el precio fijado. Aunque al principio la idea de no pagar al contado le hace titubear, al no tener que desembolsar una cantidad de manera inmediata, siente seguridad. A primera vista, la opción de crédito le otorga agencia en alguna medida, pues puede comprar lo que desee sin la intervención de su avaro y tacaño esposo. Tradicionalmente, don Francisco Bringas ha excluido a su esposa de cualquier intervención en las decisiones financieras del hogar. Con el arranque de la novela, la relación entre ambos cónyuges se amolda a las leyes de la sociedad capitalista patriarcal, según la cual la mujer únicamente tiene acceso al dinero por mediación del hombre: "[Francisco Bringas] Mandábala venir a su presencia, y allí, con ademanes, ya que no con miradas de juez inexorable, hacía pública ostentación (solía estar presente Torres o algún otro amigo) de su soberanía doméstica” (214). Don Francisco impone con tiranía la indumentaria que su familia ha de llevar y con frecuencia

74

Lectora, 26 (2020): 67-81. ISSN: 1136-5781 D.O.I.: 10.1344/Lectora2020.26.5 
reprueba que Rosalía cambie de vestidos y gaste dinero en galas y adornos. Una vez acostumbrada a pagar a crédito y libre por una vez de los largos años de sumisión económica impuestos por su marido, Rosalía circula con soltura por las tiendas: "Pensando en estos y otros planes, recorría despacio las calles [...] deteníase ante los escaparates de modas y de joyería, y hacia mil cálculos sobre la probabilidad más o menos remota de poseer algo de lo mucho valioso y rico que veía" (244). La protagonista se embelesa ante los escaparates y la esmerada disposición visual de las tiendas: "Los ojos se le iban tras de las originales telas, y más aún tras de los admirables modelos colocados en los maniquís. En fichus, encajes, manteletas, camisetas, pellizas estaban allí las Mil y una noches de los trapos" (263-264). La ceguera temporal que sufre don Francisco concede a Rosalía el cetro del poder económico familiar. Aprovechando la transitoria enfermedad de su esposo, menudean sus compras en Sobrino Hermanos. A pesar de las preocupaciones financieras que comienzan a acosar la economía doméstica, Rosalía continúa aprovechándose de la ventaja de "entrada libre" a los almacenes, donde los comerciantes "con amabilidad infernal" exhiben sus "telas diversas y cositas de capricho" y cae "en la tentación, unas veces porque se le presentaban verdaderas gangas, otras porque el género le entraba por el ojo derecho, encendiendo todos los fuegos de su pasión trapística” (244).

\section{La manteleta parisina y el poder de los objetos femeninos}

Durante una de sus incursiones a Sobrino Hermanos, Rosalía descubre una manteleta parisina, aditamento exterior de abrigo derivado del mantón que se introdujo en los años 1860 y que obtuvo sonado éxito entre las españolas (Gutiérrez García, 2005: 1415). El objeto de adorno, en el cual "el terciopelo, el paño y la brillante cordonería se combinaban peregrinamente" (45), se convierte en la gran obsesión de Rosalía, desatando su furor trapístico. La relación física y emocional que se desarrolla entre la manteleta y la protagonista son descritos de forma minuciosa por Galdós. En primer lugar, la compra de la hermosa prenda que "los parisienses habían hecho expresamente para ella" (99) ha sido precedida por un hábito de economía virtuosa sostenida bajo coerción y experimentada como una dolorosa privación. Este sentimiento se ha incrementado por la costumbre de comprar con amigas ricas como la marquesa, cuya actitud displicente hacia los empleados de las tiendas al mismo tiempo intimida y fascina a Rosalía. El anhelo por considerarse en términos de igualdad con la marquesa Milagros e imitar su estatus social se confunden con la intensidad de su deseo por poseer la fabulosa prenda. Esto arrastra a la protagonista a un estado de sensibilidad física y agobio febril: "Rosalía hubo de sentir frío en el pecho, ardor en las sienes, y en sus hombros los nervios le surgieron tan al vivo la sensación del contacto y peso de la manteleta, que creyó llevarla puesta" (98).

Una vez consigue hacerse con el preciado objeto, Rosalía se dedica a abarrotar el Camón con nuevas prendas. La mujer se refiere a sus artículos de vestir como 
"aquellos pedazos de su corazón que se manifestaban en el mundo real en forma de telas, encajes y cintas” (161). Dichos objetos reciben la atención y el afecto que no puede albergar hacia Francisco Bringas, con el que ha tenido cuatro hijos sin engendrar ni satisfacer ningún deseo sexual (143). Las sensaciones que experimenta en contacto con sus objetos parecen más sinceras y naturales que cualquier otra que pudiera sentir. Por ejemplo, al pensar en un sombrero siente "un bulle-bulle en su cabeza y representándose, con admirable poder de alucinación, el conjunto y las partes todas del bien descrito sombrero" (103). Incluso los objetos de moda la persiguen en sueños, cobrando matices eróticos. Mientras duerme, siente el peso de la "bonita y vaporosa tela" sobre su carne, a la que reconoce como "sus carnes" (84). Esto es, el objeto ha pasado a formar parte de Rosalía, a fundirse con su cuerpo. Sin embargo, sus objetos de adorno son más que una sustitución del cumplimiento sexual; constituyen una manifestación visible de una nueva, mas secretamente experimentada, identidad. Cada vestido, bonete y accesorio representa un vínculo tangible y material con su amiga Milagros; son prueba de que su intimidad con la dama aristocrática y su lazo con la clase alta en verdad existen.

Con el transcurrir de la novela, Rosalía miente sobre sus gastos exorbitantes y esconde en la casa prendas - batas de seda, vestidos, zapatos, bolsos, chales, pañuelos - para continuar con la apariencia de normalidad, esto es, con la economía constrictiva del hogar. En su imaginación desbordante, justifica su despilfarro: "Era una estupidez que persona de tal mérito [como ella] tuviera que esconder su buena ropa, ponérsela a hurtadillas e inventar mil mentiras para justificar el uso de diversas prendas que parecían ajustadas a su hermoso cuerpo por los mismos ángeles de la moda" (169). Los objetos, de todas las formas y colores, sellan su presencia en la historia, desbordando el territorio doméstico y comparándose con un mar turbulento: "Estaba [Rosalía] en medio de un mar de trapos, cintas y prendas, cuyas encrespadas olas llegaban hasta la puerta" (214). Tal y como se desprende del fragmento a continuación, los artículos de vestir acaparan la trama, insuflándose de vida. El uso de verbos de acción como "se arrastraba" o "se encaramaba" otorga a las prendas el carácter amenazador de grandes animales salvajes a los que no es posible domesticar:

Había allí unas veinticuatro varas de Mozambique, del de a dos pesetas vara, a cuadros, bonita y vaporosa tela que la Pipaón, en sueños, veía todas las noches sobre sus carnes. La enorme tira de trapo se arrastraba por la habitación, se encaramaba a las sillas, se colgaba de los brazos del sofá y se extendía por el suelo, para ser dividida en pedazos por la tijera de la oficiala que, de rodillas, consultaba con patrones antes de cortar. Tiras y recortes de glasé, de las más extrañas condiciones geométricas, cortados al bies, veíanse sobre el baúl [...]. Trozos de brillantes raso, de colores vivos, eran los toques

76

Lectora, 26 (2020): 67-81. ISSN: 1136-5781 D.O.I.: 10.1344/Lectora2020.26.5 
calientes, aún no salidos de la paleta diseminadas por toda la pieza entre mal enroscadas cintas y fragmentos de encaje [...]. Las dos mujeres no podían andar por allí sin que sus faldas se enredaran en el Mozambique y en unas veinte varas de poplín azul marino que se había caído de la silla y se entrelazaban con las tiras de un foulard. [...] Sobre el sofá, media docena de figurines ostentaban en mentirosos colores damas imposibles. (119-120; la cursiva es mía)

Ya dueña de su soñada manteleta, Rosalía es poseída por un intenso deseo material que adquiere visos de alucinación. Según crece su obsesión, es retratada como una mujer "fuera de control", figura decimonónica frecuente y tan extendida como la de "ángel del hogar" (Aldaraca, 1991: 60). Enmarcada por su manteleta, Rosalía es descrita "corriendo de tienda en tienda, bajo la acción intoxicante de una embriaguez de trapos" (104) o "sin poder resistir la tentación [...] dejándose llevar de su apasionado afán" (164). Su contacto con objetos fuera del alcance de su poder pecuniario la había llevado "insensiblemente, a un terreno erizado de peligros" (118).

A este respecto, el discurso decimonónico en torno al consumo de la moda alude con frecuencia al deseo femenino insaciable e irracional (Merish, 2000: 8). En la época, proliferan las advertencias acerca de los deseos anómalos y difíciles de controlar que ocasiona la moda en la mujer, incluso originando irreparables daños físicos y psicológicos (Merish, 2000: 9). Bajo la pluma de Galdós, Rosalía simboliza la popular imagen de la mujer consumidora y devoradora que Susan David Bernstein describe como "the madame monster of the market place, the woman dazzled by her desires for material acquisitions and sensual pleasures" (1994: 217). Bernstein explica que la práctica del consumo y la independencia económica por parte de la mujer se percibían como un acto de desafío en flagrante oposición a la estructura patriarcal del XIX. Al hilo de esto, La de Bringas muestra el peligroso trastorno físico y mental al que se expone la mujer derrochadora que compra de espaldas al control masculino.

Según progresa la novela, Rosalía concede un elevado préstamo a la marquesa Milagros, lo que le permite entrar en la red financiera a través de la puerta de lo que ella percibe como inversión de capital, actividad privativa del hombre. Una vez que su aristocrática amiga incumple el préstamo y es amenazada por el prestamista judío Torquemada, la protagonista se dirige a su pretendiente Manuel Pez en busca de ayuda. Rosalía ofrece su cuerpo a Pez a cambio de una "garantía" con la que poder saldar su deuda, convirtiéndose ella misma en una mercancía que porta un determinado valor económico en el mercado. El elemento económico de intercambio en esta relación ilícita fracasa de nuevo, ya que Pez es un noble arruinado y Rosalía no obtiene nada a cambio de la transacción. Como declara la esposa burguesa, "Ignominia grande era venderse; pero ¡darse de balde!” (273; la cursiva es mía). De manera significativa, Pez "compra" a Rosalía sin excesiva dificultad, pues intuye que 
es una mujer sin desarrollar sexualmente, cuyas reservas de pasión no se gastan en los hombres sino en el lujo y las compras: "Dijo [Manuel Pez] que [Rosalía] era como los toros, que acuden más al trapo que al hombre" (229).

El admonitorio cierre de la novela recalca las dañinas consecuencias que detentan las compras para la mujer. Rosalía falla en todos sus deberes como madre y esposa a causa de su afán desenfrenado por la indumentaria. No es solo infiel a su marido - no por verdadera pasión sino por interés material-, sino que por añadidura descuida la economía familiar e incurre en préstamos que después es incapaz de saldar. La protagonista prepara baratos e interminables cocidos en el hogar familiar para financiar su apariencia exterior de respetabilidad, sacrificando la salud y bienestar general de su esposo e hijos en aras de la moda. La asociación del consumo femenino con la decadencia moral resulta patente. ${ }^{7}$ Como Pérez Galdós sugiere entre líneas, el espíritu empresarial solo puede estar en manos de los hombres, al ser los únicos capaces de establecer una relación racional con el dinero. La narración encierra un mensaje de advertencia para la mujer de clase media y alta que, incapaz de controlar sus prácticas consumistas, encuentra su castigo en la prostitución y consiguiente ruina económica familiar. ${ }^{8}$ Ello refuerza las bases del capitalismo patriarcal, fundamentado en la dependencia económica de la mujer respecto al hombre. Desde este punto de vista aleccionador, el consumo femenino es incompatible con los valores éticos provenientes de la sociedad burguesa. Como puntualiza el autor canario de forma crítica: "esta pasión mujeril [la moda] que hace en el mundo más estragos que las revoluciones" (94). Desde esta perspectiva, la intromisión de Rosalía en la geografía urbana desvela el seductor y pernicioso mundo de la vanidad material que esconde la ciudad para la mujer. Así también, la moda constituye una trampa para mujeres de la mesocracia que obedecen sin control a las necesidades creadas de forma explícita por el capitalismo incipiente.

Sin embargo, en el texto caben otras lecturas. La fascinación por los objetos de moda puede interpretarse como una actividad transgresora femenina que, por tanto, precisa ser vigilada por la autoridad patriarcal. Rosalía, a pesar de su avidez consumista, desvela un talento sartorial sin parangón. De igual forma, la marquesa de Tellería detenta un gusto visionario por la indumentaria "que le da un palmetazo al

\footnotetext{
${ }^{7}$ Es de anotar aquí el paralelismo de La de Bringas con la célebre novela de Gustave Flaubert Madame Bovary (1856). De forma pareja a Rosalía Pipaón, la caída moral de Emma Bovary va asociada a su pasión por objetos de moda.

${ }^{8}$ Una idea similar se halla en la novela La desheredada (1881) de Pérez Galdós. La protagonista Isidora Rufete, a causa de sus pretensiones aristocráticas y adicción a las compras, cae en el trastorno mental y acaba finalmente por prostituirse.
}

78

Lectora, 26 (2020): 67-81. ISSN: 1136-5781 D.O.I.: 10.1344/Lectora2020.26.5 
célebre Worth" (121). ${ }^{9}$ La inclinación hacia todo aquello que suponga novedad, la vocación artística a la hora de coser, remendar, imaginar prendas y anticiparse a los estilos por venir hacen de Rosalía un agente y partícipe en el espíritu de los tiempos modernos. Por medio de prendas de vestir, reinventa su identidad y su personalidad se enriquece a través de cierto inconformismo, al no acatar las normas establecidas ni en su hogar ni en la sociedad. Asimismo, inmersa en el núcleo urbano, disfruta, aunque sea por un breve periodo de tiempo, de relativo poder financiero, codeándose con miembros de la aristocracia.

Todo ello pone de manifiesto hasta qué punto la mujer de finales de siglo logró a través de objetos materiales navegar los límites tradicionales de lo femenino, adquiriendo un rol determinante en la esfera pública. Si la moda tradicionalmente se ha asumido como restrictiva para la mujer y ha sido reputada como un dispositivo opresor de obediencia y sumisión a la estructura patriarcal, de manera paradójica, también le ha otorgado una vía de autoafirmación y expresión de su identidad (Wilson, 1987: 13; Parkins, 2002: 501). En última instancia, este artículo enfatiza la productividad que posee el terreno de la moda, ámbito con frecuencia no incluido en los estudios feministas, a la hora de redefinir los roles de género y explorar los discursos culturales que se imprimen en el cuerpo con el devenir de la historia cultural.

\section{REFERENCIAS BIBLIOGRÁFICAS}

Aldaraca, Bridget A. (1991), El Ángel del Hogar: Galdós and the Ideology of Domesticity in Spain, Chapel Hill, University of North Carolina Press.

Appadurai, Arjun (1988), "Introduction: Commodities and the Politics of Value", The Social Life of Things: Commodities in a Cultural Perspective, Arjun Appadurai (ed.), Cambridge, Cambridge UP: 3-63.

Baudelaire, Charles (1964), The Painter of Modern Life and Other Essays, Jonathan Mayne (trad.), Nueva York, Phaidon. [1863]

Beaujout, Ariel (2011), Victorian Fashion Accessories, Oxford, Berg Publishers.

Benjamin, Walter (1999), The Arcades Project, Howard Eiland y Kevin McLaughlin (trads.), Cambridge, Harvard UP. [1982]

Bernstein, Susan David (1994), "Dirty Reading: Sensation Fiction, Women, and Primitivism”, Criticism, 36 (2): 213-241.

Blanco Carpintero, Marta (2010), La indumentaria femenina burguesa y el fenómeno de la moda en las novelas de Galdós: de Doña Perfecta a Miau, Tesis

\footnotetext{
${ }^{9}$ Para una aproximación al modisto británico Charles Worth, radicado en París y creador de la alta costura, remito al estudio de Diana de Marly Worth: Father of Haute Couture (1990).
} 
doctoral, Madrid, Universidad Complutense de Madrid, 20/12/2010. <https://ucm.on.worldcat.org/oclc/1025617806>

Breward, Cristopher (1999), The Hidden Consumer: Masculinities, Fashion and City Life, 1860-1914, Manchester, Manchester UP.

De Marly, Diana (1990), Worth: Father of Haute Couture, Teaneck, Holmes \& Meier Publishers.

Díaz Marcos, Ana María (2006), La edad de seda: representaciones de la moda en la literatura española (1782-1926), Cádiz, Universidad de Cádiz.

Entwistle, Joanne (2000), The Fashioned Body: Fashion, Dress and Modern Social Theory, Cambridge, Polity Press.

Felski, Rita (1995), The Gender of Modernity, Cambridge \& Londres, Harvard UP.

Fernández, Pura, Luisa Elena Delgado y Jo Labanyi (2015), "Introduction”, Engaging the Emotions in Spanish Culture and History, Pura Fernández, Luisa Elena Delgado y Jo Labanyi (eds.), Nashville, Vanderbilt UP: 1-20.

Fernández Cifuentes, Luis y Roxana Pagés Rangel (2005), “La de Bringas: metrópoli, moda, identidad”, Studies in Honor of Denah Lida, May G. Berg y Lanin A. Gyurko (eds.), Potomac, Scripta Humanistica: 163-177.

Flaubert, Gustave (2016), Madame Bovary, Juan Bravo Castillo (trad.), Barcelona, Austral Singular. [1856]

Flügel, John Carl (1930), The Psychology of Clothes, Londres, Hogarth Press.

Germann, Jennifer G. y Heidi Strobel (2006), Materializing Gender in EighteenthCentury Europe, Burlington, Ashgate.

Gilloch, Graeme (1988), Myth and Metropolis. Walter Benjamin and the City, Cambridge, Polity Press.

Goggin, Maureen Doli y Beth Fowkes Tobin (2009), Material Women, 1750-1950. Consuming Desires and Collecting Practices, Burlington, Ashgate.

Gutiérrez García, María Ángeles (2005), “Un mundo burgués y la moda en la obra de Benito Pérez Galdós”, De crinolinas y polisones, Murcia, Museo de Bellas Artes de Murcia: 8-41.

Heneghan, Dorota (2015), Striking their Modern Pose. Fashion, Gender, and Modernity in Galdós, Pardo Bazán, and Picón, West Lafayette, Purdue UP.

Hiner, Susan (2010), Accessories to Modernity: Fashion and the Feminine in Nineteenth-Century France, Filadelfia, University of Pennsylvania Press.

Joseph, Abigail (2012), Queer Things. Victorian Objects and the Fashioning of Homosexuality, Tesis doctoral, Nueva York, Columbia University. $<$ https://doi.org/10.7916/D87P95GV>

Labanyi, Jo (2010), "Doing Things: Emotion, Affect, and Materiality", Journal of Spanish Cultural Studies, 11 (3/4): 223-233.

80

Lectora, 26 (2020): 67-81. ISSN: 1136-5781 D.O.I.: 10.1344/Lectora2020.26.5 
Lancaster, Bill (1995), The Department Store: A Social History, Londres, Leicester UP.

Laver, James (1945), Taste and Fashion. From the French Revolution to the Present Day, Londres, Harrap and Company.

Merish, Lori (2000), Sentimental Materialism: Gender, Commodity Culture, and Nineteenth-Century American Literature, Durham, Duke UP.

Miller, Michael B. (1981), The Bon Marché: Bourgeois Culture and the Department Store, 1869-1920, Princeton, Princeton UP.

Parkins, Wendy (ed.) (2002), Fashioning the Body Politic. Dress, Gender, Citizenship, Nueva York, Berg.

Pérez Galdós, Benito (2004), La de Bringas, Alda Blanco y Carlos Blanco Aguinaga (eds.), Madrid, Cátedra. [1884]

-(2018), La desheredada, Salamanca, Editorial Anaya. [1881]

Perrot, Philippe (1994), Fashioning the Bourgeoisie: A History of Clothing in the Nineteenth Century, Princeton, Princeton UP.

Rodríguez, Rodney T. (1985), "El trasfondo económico y moral de La de Bringas", Letras de Deusto, 15 (33): 165-173.

Slater, Don (1997), Consumer Culture and Modernity, Cambridge, Polity Press.

Soldevila, Carlos (1950), La moda ochocentista, Barcelona, Argos.

Steele, Valerie (1988), Paris Fashion: A Cultural History, Oxford, Oxford UP.

Tilley, Christopher (2006), "Introduction: Theoretical Perspectives", Handbook of Material Culture, Cristopher Tilley et al. (eds.), Londres, SAGE: 7-12.

Tsuchiya, Akiko (1993), "The Construction of the Female Body in Galdós's La de Bringas”, Romance Quarterly, 40: 35-47.

Tubert, Silvia (1997), "Rosalía de Bringas: el erotismo de los trapos", Bulletin of Hispanic Studies, 74 (4): 371-387.

Valis, Noël (2003), The Culture of Cursilería. Bad Taste, Kitsch, and Class in Modern Spain, Durham, Duke UP.

Wilson, Elizabeth (1987), Adorned in Dreams: Fashion and Modernity, Berkeley, University of California Press.

Zola, Émile (2013), El paraíso de las damas, María Teresa Gallego Urrutia y Amaya García (trads.), Barcelona, Alba Editorial. [1883] 